\title{
RANKL/RANK interaction promotes the growth of cervical cancer cells by strengthening the dialogue between cervical cancer cells and regulation of IL-8 secretion
}

\author{
WEN-QING SHANG ${ }^{1,2}$, HUI LI $^{2}$, LI-BING LIU ${ }^{2}$, KAI-KAI CHANG ${ }^{2}$, JIA-JUN YU $^{2}$, \\ FENG XIE ${ }^{3}$, MING-QING LI ${ }^{2,4,5}$ and JIN-JIN YU ${ }^{1}$ \\ ${ }^{1}$ Department of Obstetrics and Gynecology, The Affiliated Hospital of Jiangnan University, Wuxi, Jiangsu 214062; \\ ${ }^{2}$ Laboratory for Reproductive Immunology, Hospital of Obstetrics and Gynecology, Fudan University \\ Shanghai Medical College; ${ }^{3}$ Medical Center of Diagnosis and Treatment for Cervical Diseases, \\ Hospital of Obstetrics and Gynecology, Fudan University; ${ }^{4}$ Shanghai Key Laboratory of Female Reproductive \\ Endocrine Related Diseases, Shanghai 200011; ${ }^{5}$ NPFPC Key Laboratory of Contraceptive Drugs and Devices, \\ Shanghai Institute of Planned Parenthood Research, Shanghai, P.R. China
}

Received June 9, 2015; Accepted August 4, 2015

DOI: $10.3892 / o r .2015 .4303$

\begin{abstract}
Receptor activator for nuclear factor $\kappa \mathrm{B}$ ligand (RANKL) is a member of the tumor necrosis factor (TNF) family. The interaction between RANKL and its receptor RANK plays an important role in the development and function of diverse tissues. However, the expression and role of RANKL in cervical cancer are still unknown. In the present study, we found that RANKL and RANK were highly co-expressed in cervical cancer. HeLa and $\mathrm{SiHa}$ cells secreted soluble RANKL (sRANKL), expressed member RANKL (mRANKL) and RANK. Recombinant human RANKL protein had no effect on the viability of HeLa and SiHa cells. Yet, blocking RANKL with an anti-human RANKL neutralizing antibody ( $\alpha$-RANKL) or recombinant human osteoprotegrin (OPG) protein resulted in the downregulation of Ki-67 and B-cell lymphoma 2 (Bcl-2) expression and an increase in Fas and Fas ligand (FasL) expression, as well as a high level of viability and a low level of apoptosis in the $\mathrm{HeLa}$ and $\mathrm{SiHa}$ cells. In addition, $\alpha$-RANKL led to a decrease in IL-8 secretion. Recombinant human IL-8 protein reversed the effect of $\alpha$-RANKL on the expression of proliferation- and apoptosis-related molecules, and proliferation and apoptosis in the HeLa and SiHa cells. The present study suggests that a
\end{abstract}

Correspondence to: Dr Ming-Qing Li, Laboratory for Reproductive Immunology, Hospital of Obstetrics and Gynecology, Fudan University Shanghai Medical College, 413 Zhaozhou Road, Shanghai 200011, P.R. China

E-mail:mqli@fudan.edu.cn

Dr Jin-Jin Yu, Department of Obstetrics and Gynecology, The Affiliated Hospital of Jiangnan University, 200 Huihe Road, Wuxi, Jiangsu 214062, P.R. China

E-mail: yujjwx@126.com

Key words: RANKL, RANK, cervical cancer cells, viability, apoptosis, IL-8 high level of mRANKL/RANK expression in cervical cancer lesions plays an important role in the rapid growth of cervical cancer cells possibly through strengthening the dialogue between cervical cancer cells and regulation of IL-8 secretion, which may be a possible target for cervical cancer therapy.

\section{Introduction}

Cervical cancer, a gynecological malignancy, is both the fourth most common cause of cancer and the fourth most common cause of cancer-related mortality among women worldwide (1). There are $\sim 528,000$ new cases diagnosed every year worldwide, and approximately a third are Chinese (2). Radiotherapy and chemotherapy are the two main effective treatments for advanced cervical cancer. Yet, more than onethird of patients develop recurrence or metastatic disease, despite the availability of modern advanced technology. Since the pathogenesis of cervical cancer remains unclear, appropriate cervical cancer treatments are still difficult to achieve, particularly individual control strategies.

Receptor activator of nuclear factor $\kappa \mathrm{B}$ ligand (RANKL, also called TNFSF11, OPGL and TRANCE) is a member of the tumor necrosis factor (TNF) superfamily. After binding to its cognate receptor RANK (also called TNFSF11A, TRANCE-R and CD265), they are essential regulators of osteoclast differentiation and thereby fundamental regulators of bone physiology, bone remodeling $(3,4)$, mammary gland development during pregnancy $(5,6)$, establishment of the thymic microenvironment (7) and bone metastasis of cancer $(8,9)$. The co-expression of RANKL and RANK has been observed in diverse types of malignant human tumors, and was found to correlate with metastasis and poor patient survival (10). Moreover, RANKL promotes the migration and invasion of several types of human tumor cells expressing its receptor RANK (11-14). However, the role of the RANKLRANK axis in modulating the behaviors of cervical cancer cells is mostly unknown. 
The chemokines, a family of small cytokines or signaling proteins secreted by cells, regulate the trafficking of leukocytes to sites of inflammation and recirculation in secondary lymphatics by interaction with chemokine receptors $(15,16)$. In addition, chemokines regulate multiple behaviors of tumor cells, including growth migration, invasion and angiogenesis $(17,18)$. Our previous study showed that chemokine CXCL8 (also known as IL-8) induced by hypoxia stimulated the proliferation of cervical cancer cells (19). In addition, Secchiero et al showed that the RANKL/RANK system may contribute to the pathogenesis of $\mathrm{B}$ chronic lymphocytic leukemia (B-CLL) by upregulating IL-8 (20). However, the expression and possible role of RANKL/RANK in cervical cancer cells and the relationship with IL- 8 remain elusive.

Therefore, the present study aimed to explore whether cervical cancer cells co-express RANKL and RANK, and whether the RANKL/RANK system regulates the proliferation and apoptosis of cervical cancer cells by modulating the IL-8 level in vitro.

\section{Materials and methods}

Tissue collection. Written informed consent was obtained from all patients before sampling. All tissue samples were solely obtained for research purposes and obtained with informed consent in accordance with the requirements of the Research Ethics Committee of the Obstetrics and Gynecology Hospital of Fudan University. Samples from 12 patients in International Federation of Gynecology and Obstetrics (FIGO) stages of cervical cancer were obtained from women 31-58 years of age. All the samples were histologically confirmed according to established criteria, and squamous cell carcinoma was diagnosed in all patients.

Immunohistochemistry (IHC). Immunohistological staining was performed as previously described $(19,21)$. Paraffin sections $(5 \mu \mathrm{m})$ of tissues from cervical cancer $(\mathrm{n}=12)$ were dehydrated in graded ethanol, and incubated with hydrogen peroxide in $1 \%$ bovine serum albumin (BSA)/TBS to block endogenous peroxidase. The cervical cancer samples were then incubated with the mouse anti-human RANKL $(25 \mu \mathrm{g} / \mathrm{ml})$ or the RANK $(25 \mu \mathrm{g} / \mathrm{ml})$ (both from R\&D Systems, USA) antibody or mouse IgG isotype antibody overnight at $4^{\circ} \mathrm{C}$ in a humid chamber. After washing three times with TBS, the sections were overlaid with peroxidase-conjugated anti-mouse IgG antibody (Golden Bridge International, Inc., Beijing, China), and the reaction was developed with 3,3'-diaminobenzidine $(\mathrm{DAB})$ and counterstained with hematoxylin. The experiments were repeated five times.

Cell culture. Cervical epidermoid carcinoma HeLa and SiHa cells were purchased from the Chinese Center for Type Culture Collection (CCTCC). HeLa and SiHa cells were grown in Dulbecco's modified Eagle's medium (DMEM)/F-12 medium supplemented with $5 \%$ fetal bovine serum (FBS) (both from HyClone, Logan, UT, USA).

BrdU cell proliferation and apoptosis assays. HeLa and $\mathrm{SiHa}$ cells were seeded at a density of $5 \times 10^{3}$ cells/well into 96-well flat-bottom microplates (for BrdU cell proliferation assay) or $2 \times 10^{5}$ cells/well into 12 -well flat-bottom microplates (for apoptosis assay), and were subsequently starved with DMEM/F-12 medium containing $1 \%$ FBS for $12 \mathrm{~h}$ before treatment, and were then stimulated with rhRANKL protein (1, 10 or $100 \mathrm{ng} / \mathrm{ml})$, anti-RANKL neutralizing antibody $(\alpha$-RANKL; $0.1,1$ or $10 \mu \mathrm{g} / \mathrm{ml})$ or recombinant human osteoprotegrin protein (rhOPG) $(1,10$ or $100 \mathrm{ng} / \mathrm{ml}$ ) (all from R\&D Systems) for 24 or $48 \mathrm{~h}$. In addition, vehicle was added to various wells as a negative control. Then the abilities of the HeLa and SiHa cells to proliferate and undergo apoptosis were detected with BrdU cell proliferation assay (Millipore, Darmstadt, Germany) and Annexin V-FITC apoptosis assay (Invitrogen, USA) according to the manufacturer's instructions, respectively. Each experiment was performed in six parallel wells and repeated three times.

Enzyme-linked immunosorbent assay (ELISA) for sRANKL and IL-8 determination. HeLa ( $2 \times 10^{5}$ cells/well) and SiHa cells ( $2 \times 10^{5}$ cells/well) were seeded into 24 -well plates and cultured for $48 \mathrm{~h}$. Then culture supernatants were harvested, centrifuged to remove cellular debris, and then stored at $-80^{\circ} \mathrm{C}$ until being assayed by ELISA. In addition, the secretion of RANKL by the supernatants was detected using a human RANKL ELISA kit (BioVendor GmbH, Kassel, Germany) according to the manufacturer's instructions.

In addition, HeLa and SiHa cells $\left(2 \times 10^{5}\right.$ cells/well $)$ were treated with $\alpha$-RANKL $(10 \mu \mathrm{g} / \mathrm{ml})$ for $48 \mathrm{~h}$ with vehicle as a control. Then, the IL- 8 level in the supernatant from the HeLa and SiHa cells was analyzed by ELISA (Shanghai ExCell Biology, Inc., Shanghai, China) according to standard procedures.

Flow cytometry (FCM). HeLa $\left(2 \times 10^{5}\right.$ cells/well) and SiHa cells ( $2 \times 10^{5}$ cells/well) were cultured for $48 \mathrm{~h}$, and then digested with $0.25 \%$ trypsin only for $30-50 \mathrm{sec}$, blown-off gently and washed with phosphate-buffered saline (PBS). After blocking with $10 \%$ FBS, the recovered cells were mixed with phycoerythrin (PE)-conjugated RANKL (BioLegend, San Diego, CA, USA) or RANK (PE; R\&D Systems) antibody in darkness for $30 \mathrm{~min}$ at room temperature. As a negative control, an isotope control (BioLegend) was used. After incubation, the cells were washed and immediately analyzed by a flow cytometer (FACSCalibur; BD, USA) and CellQuest software (Becton-Dickinson, USA). The statistical analysis was conducted using isotype-matched controls as references. The experiments were repeated three times.

HeLa and SiHa cells were incubated with $\alpha$-RANKL $(10 \mu \mathrm{g} / \mathrm{ml})$ or $\mathrm{rhOPG}(100 \mathrm{ng} / \mathrm{ml})$ for $48 \mathrm{~h}$, with vehicle as a control. Then the expression levels of Ki-67 (PE; BioLegend), B-cell lymphoma 2 (Bcl-2) [fluorescein isothiocyanate (FITC); BD Biosciences, San Jose, CA, USA), Fas allophycocyanin (APC), Fas ligand (FasL) (PE) (both from BioLegend), CXCR1 (PE) and CXCR2 (PE) (both from R\&D Systems) in the HeLa and SiHa cells were analyzed by FCM, respectively.

Moreover, in order to investigate whether IL-8 is involved in the regulation of $\mathrm{HeLa}$ and $\mathrm{SiHa}$ cells mediated by RANKL, we treated HeLa and SiHa cells with rhIL-8 (100 ng/ml; R\&D Systems), $\alpha$-RANKL (10 $\mu \mathrm{g} / \mathrm{ml})$ or rhIL-8 plus $\alpha$-RANKL for $48 \mathrm{~h}$. Then the expression of Ki-67, Bcl-2, 

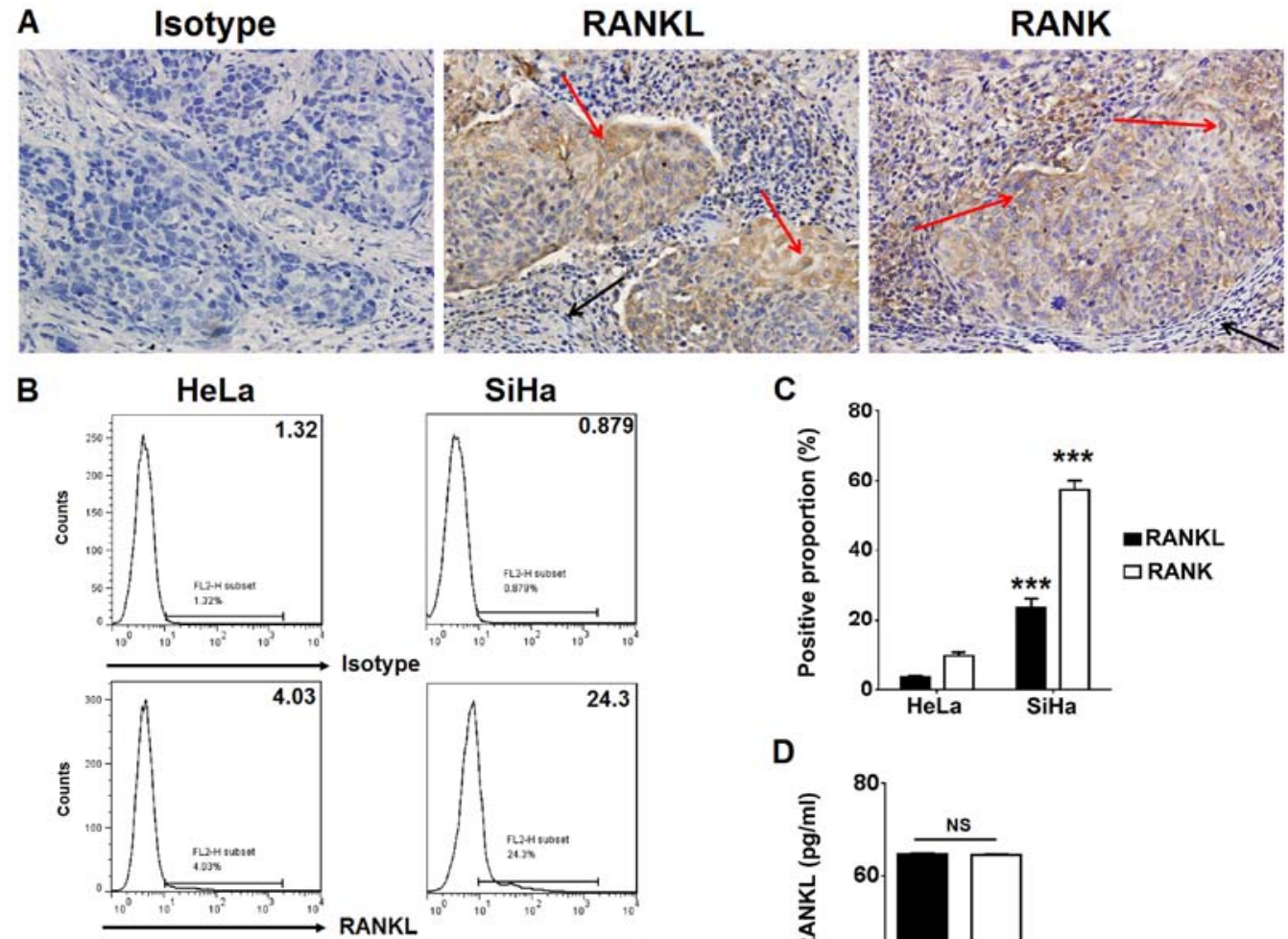

Isotype
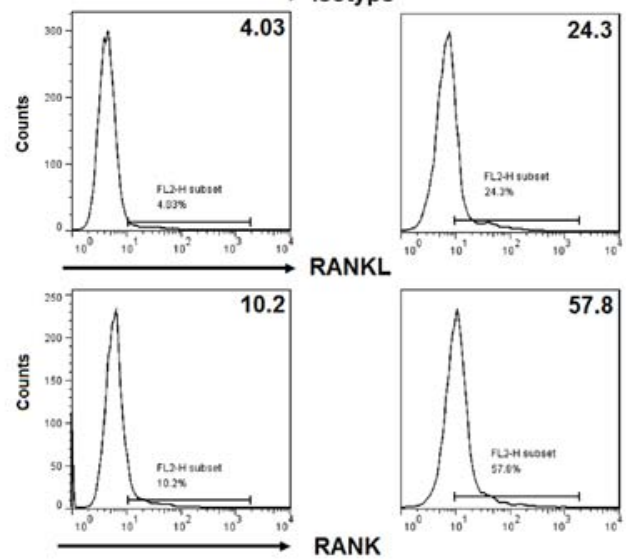

C

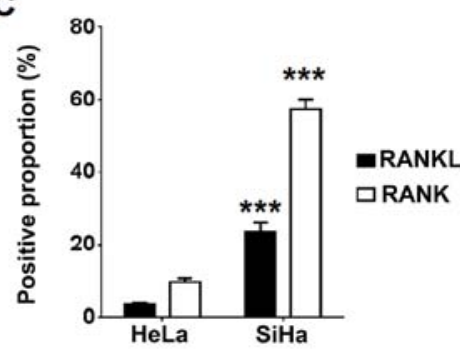

D

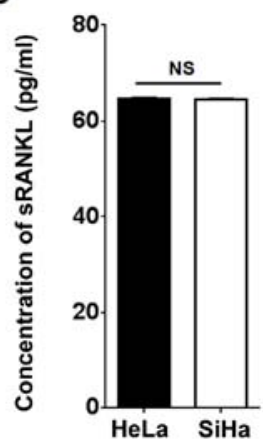

Figure 1. Cervical cancer cells highly co-express RANKL and RANK. (A) IHC analysis ( $\mathrm{n}=12$ ) for RANKL and RANK expression in cervical cancer cells (red arrows) and paracancerous cells (blank arrows). RANKL and RANK were located in the cell membrane and cytoplasm. Original magnification, $\mathrm{x} 200$. (B and C) The expression of member RANKL (mRANKL) and RANK in HeLa and SiHa cells by FCM. (D) The secretion level of soluble RANKL (sRANKL) from HeLa $\left(2 \times 10^{5}\right.$ cells/well) and SiHa cells $\left(2 \times 10^{5}\right.$ cells $/$ well $)$ after culture for $48 \mathrm{~h}$. The data are expressed as the mean \pm SEM. ${ }^{* * *} \mathrm{P}<0.01$ (Student's t-test). NS, no statistical difference.

Fas and FasL, and cell proliferation and apoptosis were assessed as previously described, respectively.

Statistical analysis. All values are shown as the mean \pm SEM. The data were analyzed with GraphPad Prism version 5 by t-test or one-way ANOVA. Differences were considered to be statistically significant at $\mathrm{P}<0.05$.

\section{Results}

Cervical cancer cells highly co-express RANKL and RANK. To analyze whether cervical cancer cells express RANKL and RANK, IHC was used to evaluate the expression of RANKL and RANK in cervical cancer tissues. As shown, compared to paracancerous cells, the cervical cancer tissues exhibited strong positive staining for RANKL and RANK (Fig. 1A). RANKL and RANK were located in the cell membrane and cytoplasm (Fig. 1A). Further analysis by FCM showed that HeLa and SiHa cells co-expressed member RANKL (mRANKL) and its receptor RANK, particularly in the SiHa cells. The percentage of RANKL and RANK-positive SiHa cells was more than 6-fold higher than that in the HeLa cells $(\mathrm{P}<0.001)$ (Fig. 1B and C). However, the result of ELISA showed that the secretion of
sRANKL from the HeLa and $\mathrm{SiHa}$ cells was at an equivalent level $(65 \mathrm{pg} / \mathrm{ml})(\mathrm{P}>0.05)($ Fig. 1D). These data suggest that a high level of RANKL/RANK expression in cervical cancer cells may play a regulatory role in the biological behavior of cervical cancer cells.

RANKL enhances the proliferation and restricts apoptosis in the HeLa and SiHa cells. In order to investigate the effect of RANKL/RANK signaling in growth regulation, we treated HeLa and SiHa cells with rhRANKL (1, 10 or $100 \mathrm{ng} / \mathrm{ml}$ ), $\alpha$-RANKL $(0.1,1$ or $10 \mu \mathrm{g} / \mathrm{ml})$ or $\operatorname{rhOPG}(1,10$ or $100 \mathrm{ng} / \mathrm{ml})$ at different concentrations. We found that rhRANKL treatment did not alter the proliferation of the HeLa and SiHa cells $(\mathrm{P}>0.05)$ (Fig. 2A and B). However, we observed that blocking RANKL/RANK interaction with $\alpha$-RANKL for 24 or $48 \mathrm{~h}$ led to a decrease in HeLa and SiHa cell proliferation, particularly at a concentration of $10 \mu \mathrm{g} / \mathrm{ml}(\mathrm{P}<0.05, \mathrm{P}<0.01$ or $\mathrm{P}<0.001$ ) (Fig. 2A and B). In addition, blocking RANKL with rhOPG had a similar effect when compared to the $\alpha$-RANKL group, but could not influence the proliferation of the HeLa cells at $24 \mathrm{~h}(\mathrm{P}>0.05)$ (Fig. 2A). The differential effect of RANKL and RANK on HeLa cells may be related to the different RANKL/RANK expression in these two cells. 
AeLa
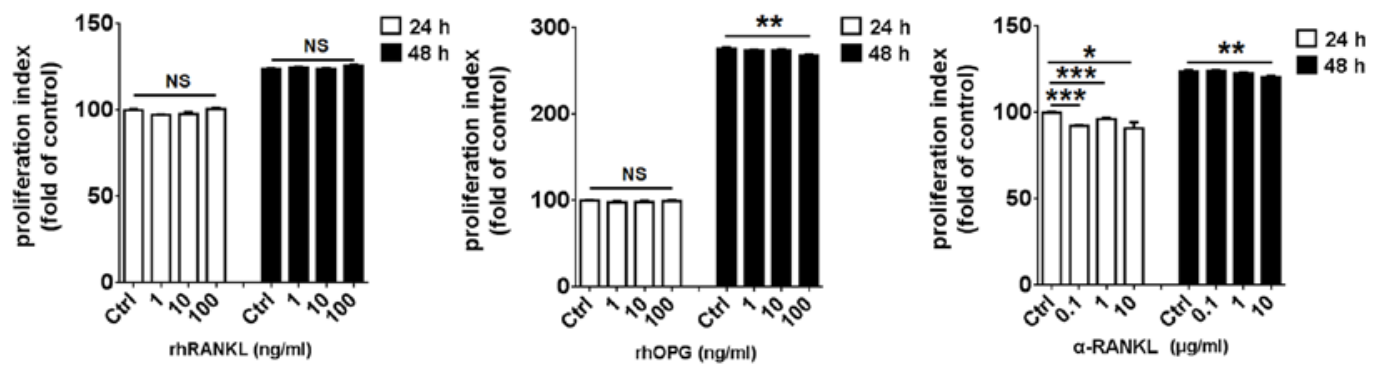

B
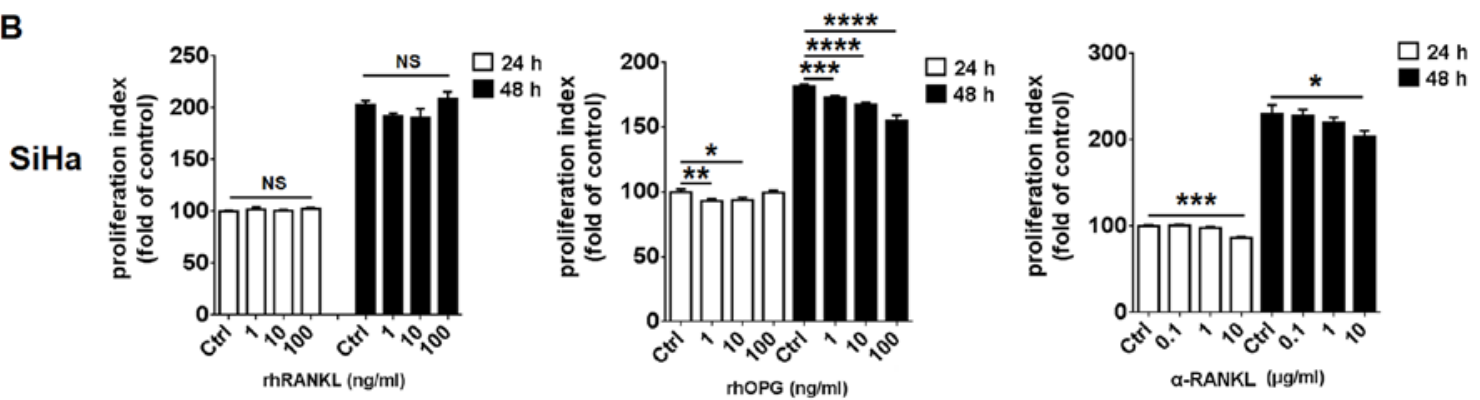

C
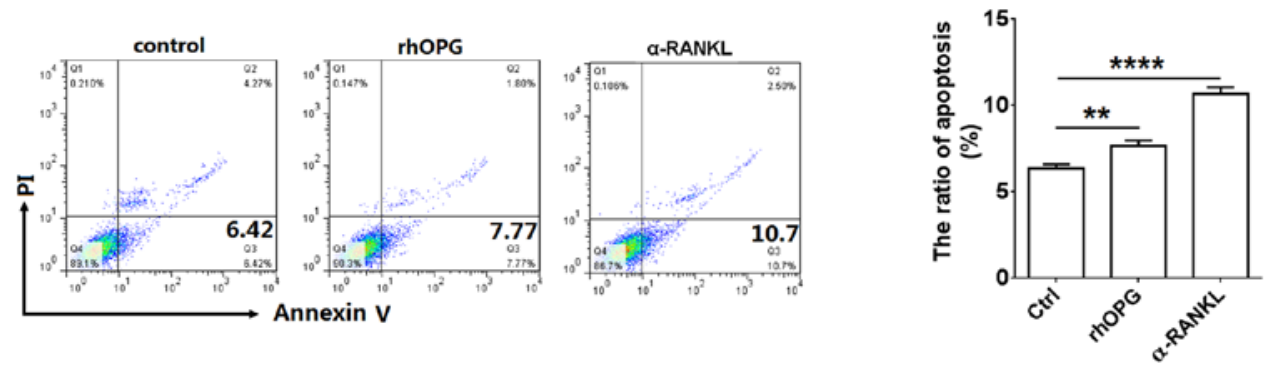

D
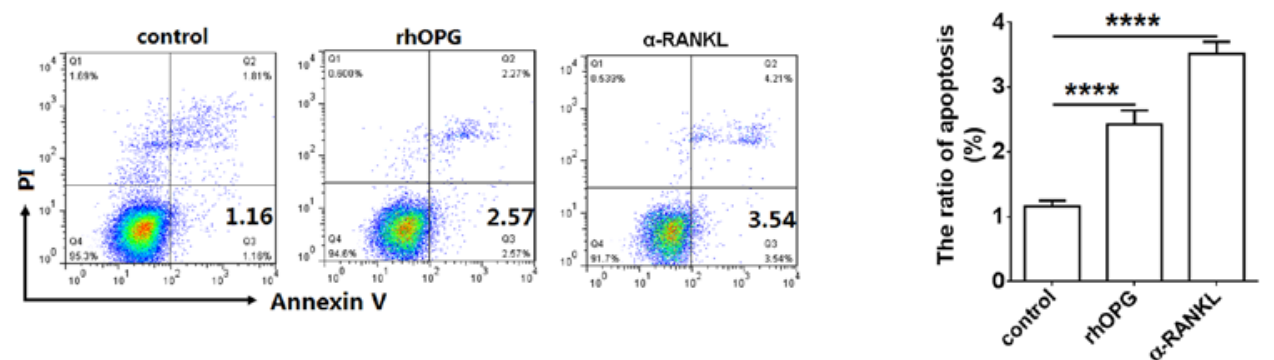

Figure 2. RANKL enhances proliferation and restricts apoptosis in HeLa and SiHa cells. (A) HeLa and (B) SiHa cells were incubated with rhRANKL (1, 10 or $100 \mathrm{ng} / \mathrm{ml}), \alpha$-RANKL $(0.1,1$ or $10 \mu \mathrm{g} / \mathrm{ml}$ ) or rhOPG $(1,10$ or $100 \mathrm{ng} / \mathrm{ml}$ ) for $24 \mathrm{~h}$ (white columns) or $48 \mathrm{~h}$ (black columns), and then cell proliferation in $\mathrm{HeLa}$ and SiHa cells was detected by BrdU proliferation assay. In addition, (C) HeLa and (D) SiHa cells were incubated with $\alpha$-RANKL (10 $\mu \mathrm{g} / \mathrm{ml})$ or rhOPG $(100 \mathrm{ng} / \mathrm{ml})$ for $48 \mathrm{~h}$, and the apoptosis in Hela and SiHa cells was analyzed by apoptosis assay. rhRANKL, recombinant human RANKL protein; $\alpha$-RANKL, anti-human RANKL neutralizing antibody; rhOPG, recombinant human OPG protein. The data are expressed as the mean \pm SEM. "P $<0.05$, ${ }^{* *} \mathrm{P}<0.01,{ }^{* * *} \mathrm{P}<0.001$ and ${ }^{* * * *} \mathrm{P}<0.0001$ (one-way ANOVA). NS, no statistical difference.

A

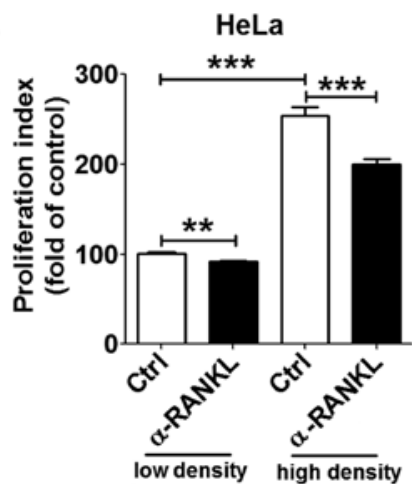

B

$\mathrm{SiHa}$

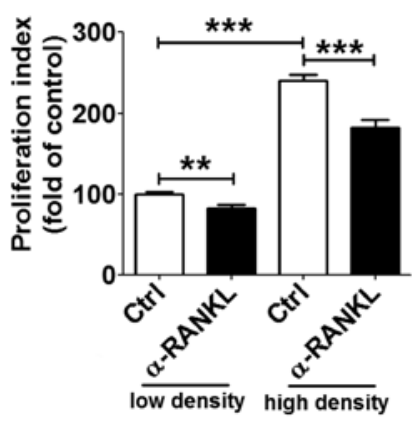

Figure 3. The proliferation of HeLa and SiHa cells. (A) HeLa and (B) SiHa cells (cell density was $4 \times 10^{3}$ or $8 \times 10^{3}$ cells in 96 -well flat-bottom microplates) were incubated with $\alpha$-RANKL $(10 \mu \mathrm{g} / \mathrm{ml})$ for $48 \mathrm{~h}$, and then cell proliferation in the HeLa and SiHa cells was detected by BrdU proliferation assay. $\alpha$-RANKL, anti-human RANKL neutralizing antibody; low density, $4 \times 10^{3}$ cells in 96-well flat-bottom microplates; high density, 8x10 ${ }^{3}$ cells in 96 -well flat-bottom microplates. The data are expressed as the mean $\pm \mathrm{SEM} .{ }^{* *} \mathrm{P}<0.01,{ }^{* * *} \mathrm{P}<0.001$. 

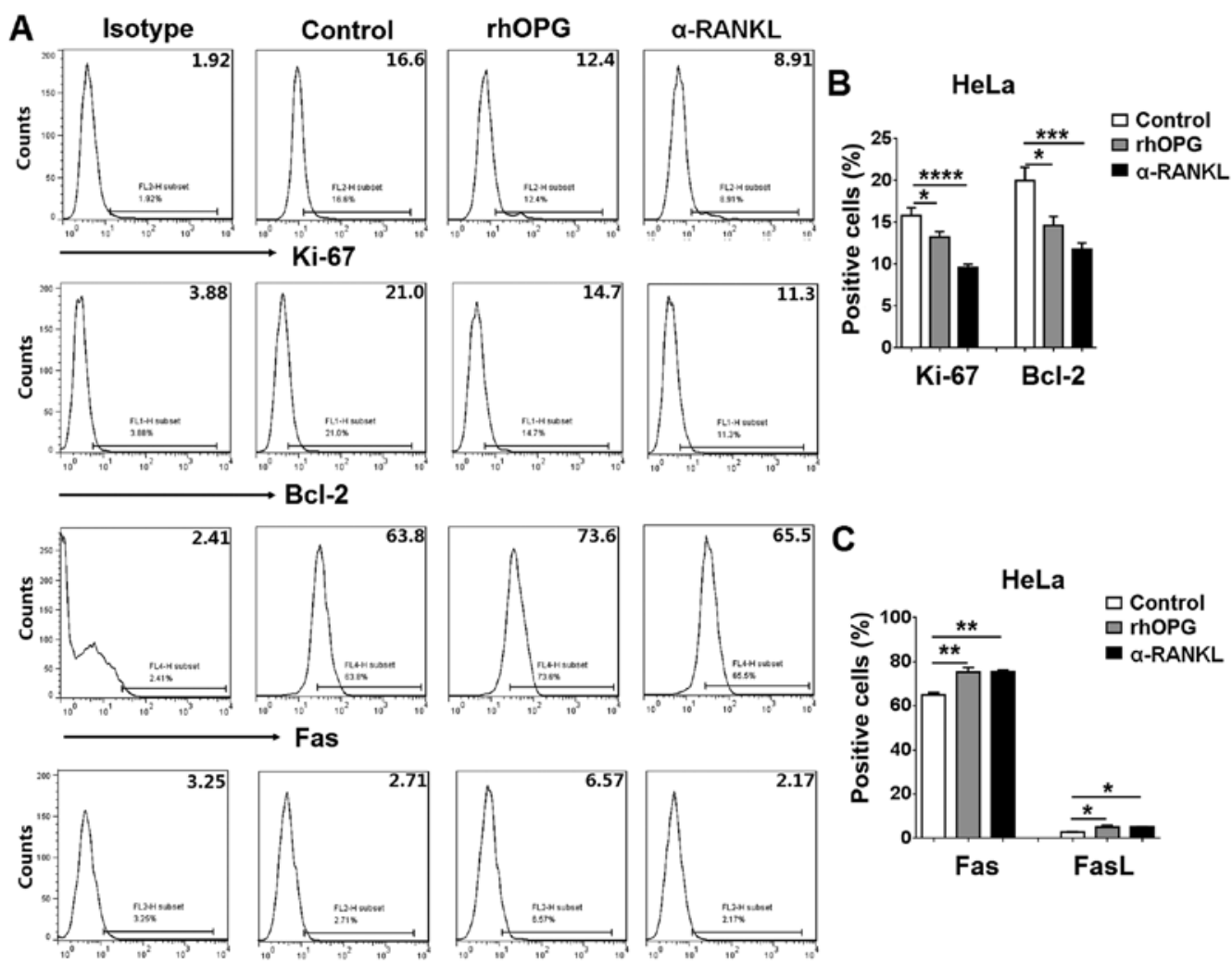

D
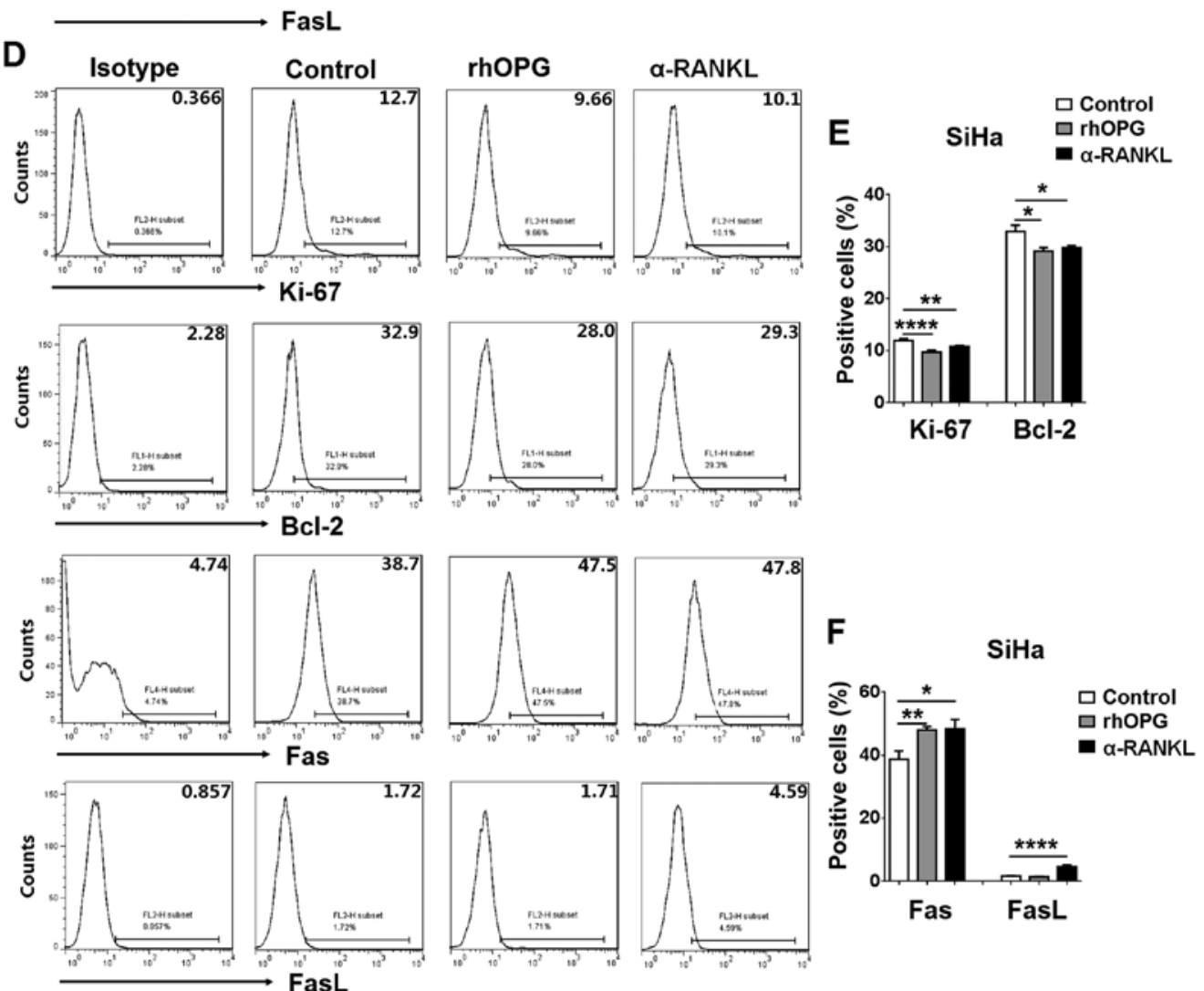

Figure 4. RANKL regulates Ki-67, Bcl-2, Fas and FasL expression in the HeLa and SiHa cells. After treatment with $\alpha$-RANKL (10 $\mu \mathrm{g} / \mathrm{ml})$ or rhOPG $(100 \mathrm{ng} / \mathrm{ml})$ for $48 \mathrm{~h}$, the expression of Ki-67, Bcl-2, Fas and FasL in (A-C) HeLa and (D-F) SiHa cells was analyzed by FCM. The data are expressed as the mean \pm SEM. ${ }^{*} \mathrm{P}<0.05,{ }^{* * *} \mathrm{P}<0.01,{ }^{* * *} \mathrm{P}<0.001$ and ${ }^{* * * *} \mathrm{P}<0.0001$ (one-way ANOVA).

Subsequently, the results of the apoptosis assay showed that incubation with $\alpha$-RANKL $(10 \mu \mathrm{g} / \mathrm{ml})$ or rhOPG $(100 \mathrm{ng} / \mathrm{ml})$ led to a significant increase in apoptosis in the HeLa $(\mathrm{P}<0.01$ or $\mathrm{P}<0.0001)$ (Fig. 2C) and $\mathrm{SiHa}(\mathrm{P}<0.0001)$ (Fig. 2D) cells. 

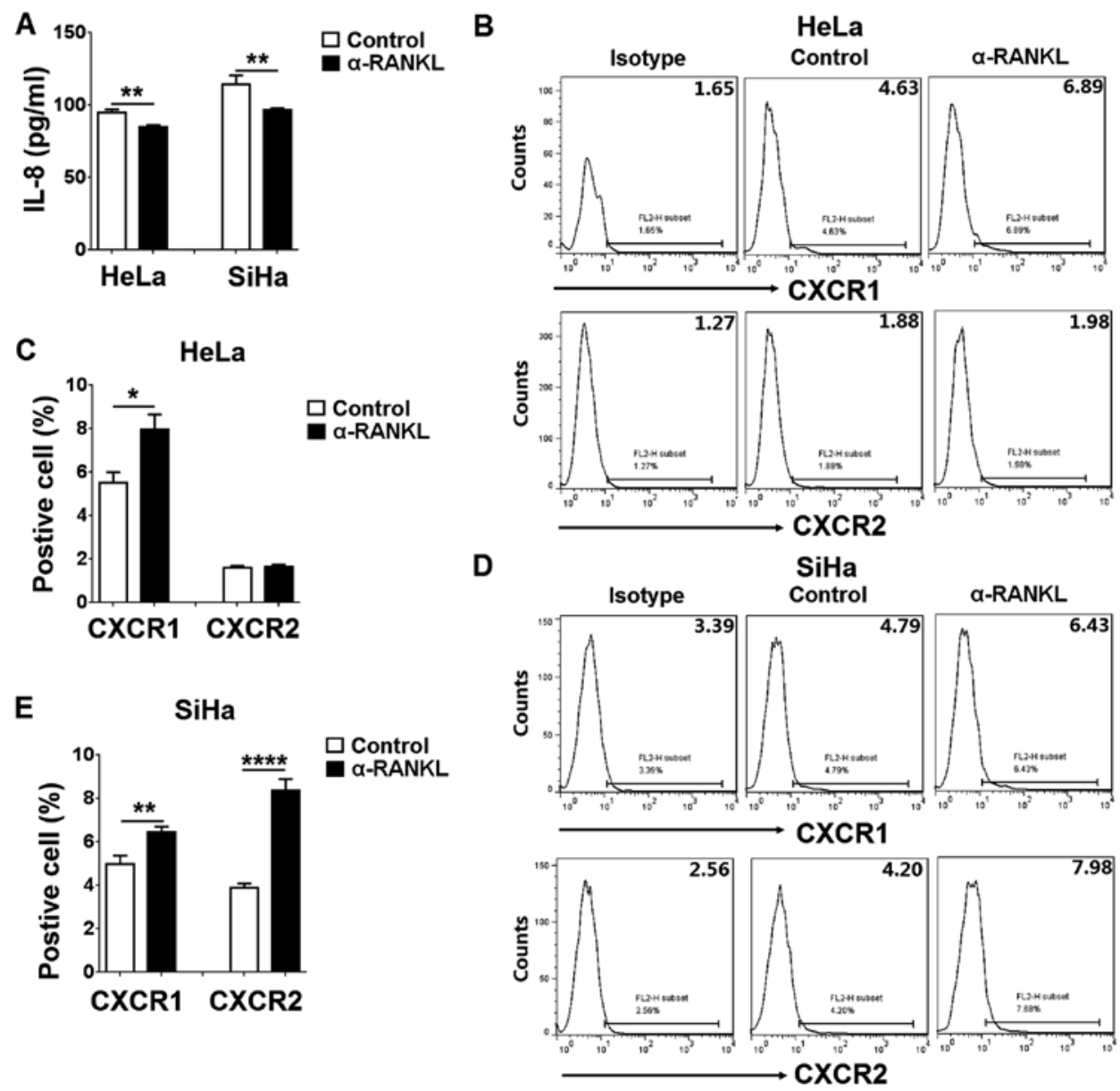

Figure 5. IL-8 secretion and expression of its receptors in HeLa and SiHa cells are regulated by RANKL. After treatment with $\alpha-\mathrm{RANKL}$ (10 $\mu \mathrm{g} / \mathrm{ml})$ for $48 \mathrm{~h}$, the secretion level of (A) IL-8, and the expression of (B-E) CXCR1 and CXCR2 in HeLa and SiHa cells were detected by ELISA and FCM, respectively. The data are expressed as the mean \pm SEM. ${ }^{*} \mathrm{P}<0.05,{ }^{* *} \mathrm{P}<0.01$ and ${ }^{* * * * *} \mathrm{P}<0.0001$ (Student's t-test).

In addition, as shown in Fig. 3, the ability of cell proliferation at a low cell density was lower than that at a high cell density $(\mathrm{P}<0.001)$. The decrease in cell proliferation induced by blocking RANKL/RANK with $\alpha$-RANKL was more apparent in the group with high cell density. These results indicate that RANKL/RANK interaction may promote the proliferation of cervical cancer cells by strengthening the dialogue between cervical cancer cells.

RANKL regulates Ki-67, Bcl-2, Fas and FasL expression in HeLa and SiHa cells. Next, FCM was performed to investigate whether RANKL regulates proliferation- and apoptosis-related molecules in cervical cancer cells. As shown in Fig. 4, both $\alpha$-RANKL and rhOPG markedly downregulated Ki-67 and Bcl-2 expression $(\mathrm{P}<0.05$, $\mathrm{P}<0.01$ or $\mathrm{P}<0.0001$ ) (Fig. $4 \mathrm{~A}$ and $\mathrm{B}$ ), and upregulated Fas and FasL expression in the HeLa cells $(\mathrm{P}<0.05$ or $\mathrm{P}<0.01$ ) (Fig. 4A and $\mathrm{C}$ ). Meanwhile, we found that stimulation with $\alpha$-RANKL or rhOPG resulted in decreases in Ki-67 and Bcl-2 expression and increases in Fas and FasL expression in the SiHa cells $(\mathrm{P}<0.05, \mathrm{P}<0.01$ or $\mathrm{P}<0.0001)$ (Fig. 4D-F). Collectively, these data indicate that the regulation of expression of these proliferation- and apoptosis-related molecules may be involved in the effect of RANKL on the proliferation and apoptosis in cervical cancer cells.
IL-8 secretion and its receptor expression in HeLa and SiHa cells are regulated by RANKL. To know the potential effect of RANKL on IL-8 and its receptors (CXCR1 and CXCR2) in cervical cancer cells in vitro, we detected IL-8 secretion, and CXCR1 and CXCR2 expression in the HeLa and $\mathrm{SiHa}$ cells after treatment with $\alpha$-RANKL. As observed by ELISA, $\alpha$-RANKL led to a decrease in IL-8 secretion from the HeLa and SiHa cells $(\mathrm{P}<0.01)$ (Fig. 5A). In contrast, treatment with $\alpha$-RANKL gave rise to an increase in CXCR1 expression in the HeLa cells $(\mathrm{P}<0.05)$ (Fig. $5 \mathrm{~B}$ and $\mathrm{C}$ ). However, the CXCR2 level exhibited no changed $(\mathrm{P}>0.05)$ (Fig. 5B and C). The difference was that $\alpha$-RANKL treatment led to an increase in CXCR1 and CXCR2 expression in the $\mathrm{SiHa}$ cells $(\mathrm{P}<0.01$ or $\mathrm{P}<0.0001)$ (Fig. 5D and E). These opposite effects should be a style of negative feedback.

RANKL/RANK axis promotes the growth of HeLa and SiHa cells possibly by stimulating $I L-8$. Taking into account the important role of IL-8 (19) in the regulation of cervical cancer cell growth, we cultured HeLa and SiHa cells with rhIL-8, $\alpha$-RANKL or rhIL-8 plus $\alpha$-RANKL, and found that rhIL-8 alone promoted cell proliferation $(\mathrm{P}<0.05$ or $\mathrm{P}<0.01$ ) (Fig. 6A and $\mathrm{B}$ ) and inhibited the apoptosis $(\mathrm{P}<0.05)$ (Fig.6C and D) of HeLa and SiHa cells, and $\alpha$-RANKL alone had an opposite effect $(\mathrm{P}<0.05$ or $\mathrm{P}<0.01)$ (Fig. 6A-D). 
A

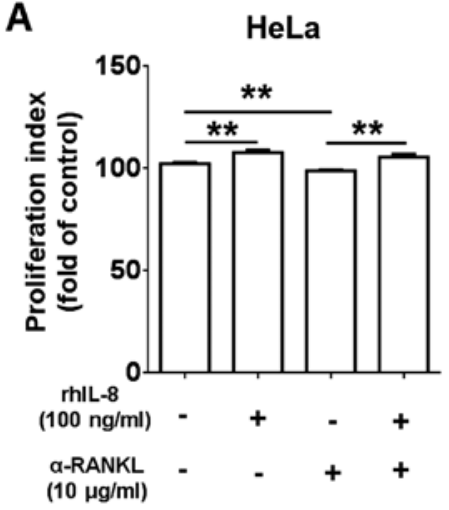

C

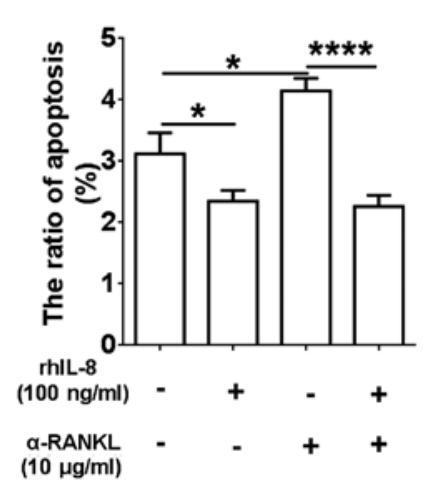

B

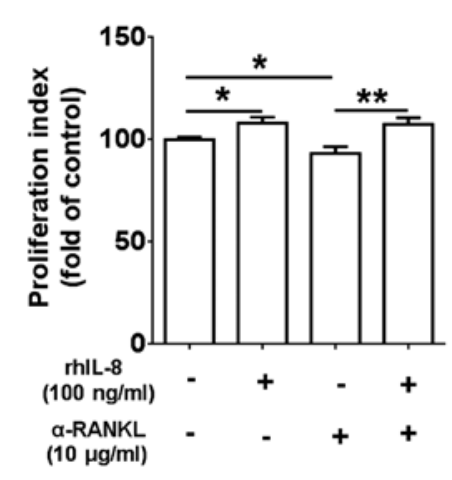

D

$\mathrm{SiHa}$

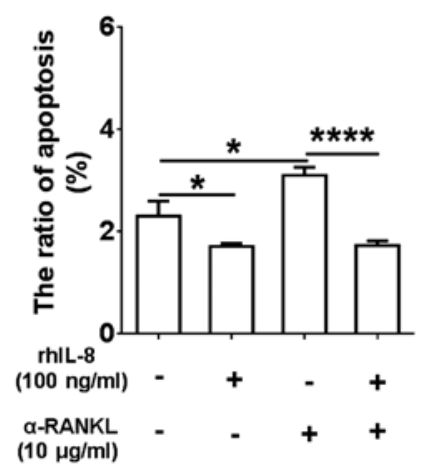

Figure 6. RANKL/RANK axis promotes HeLa and SiHa cell growth by stimulating IL-8. HeLa and SiHa cells were stimulated with rhIL-8 (100 ng/ml), $\alpha$-RANKL $(10 \mu \mathrm{g} / \mathrm{ml})$ or rhIL-8 $(100 \mathrm{ng} / \mathrm{ml})$ plus $\alpha$-RANKL $(10 \mu \mathrm{g} / \mathrm{ml})$ for $48 \mathrm{~h}$, with vehicle as the control. Then cell proliferation and apoptosis were detected by ( $\mathrm{A}$ and $\mathrm{B}$ ) BrdU proliferation and $(\mathrm{C}$ and $\mathrm{D})$ apoptosis assays, respectively. The data are represented as the mean $\pm \mathrm{SEM}$. ${ }^{*} \mathrm{P}<0.05,{ }^{* *} \mathrm{P}<0.01$ and ${ }_{* * * *} \mathrm{P}<0.0001$ (one-way ANOVA). rhIL-8, recombinant human IL-8 protein.

A

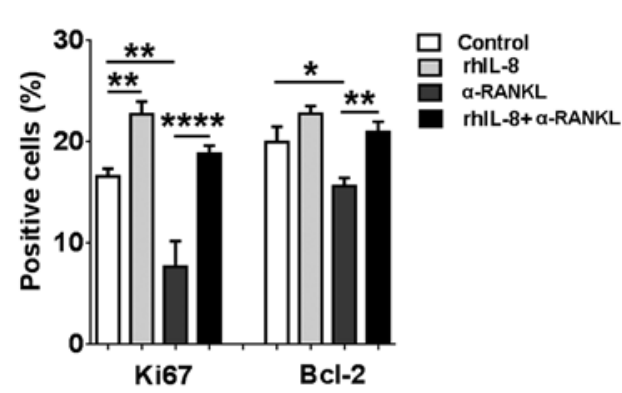

B

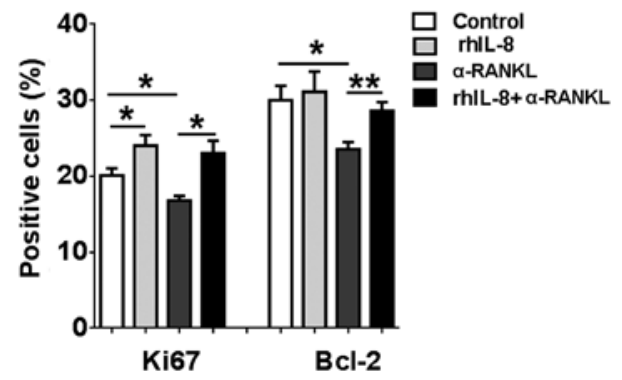

C HeLa

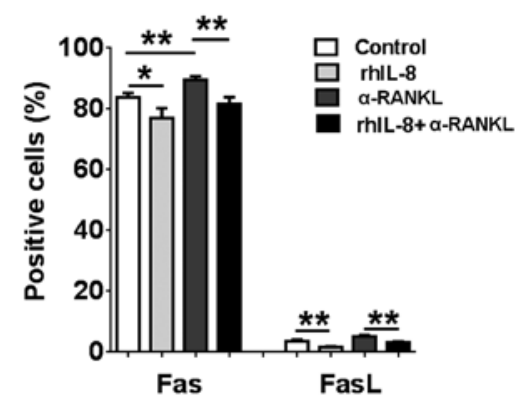

D

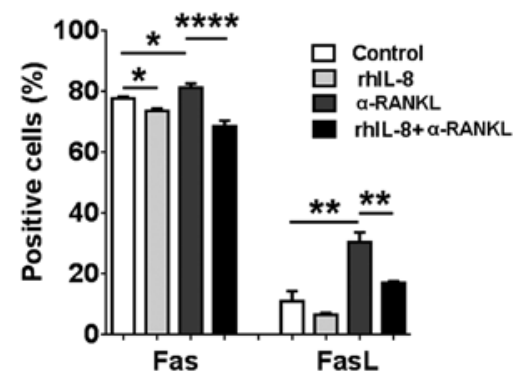

Figure 7. The regulatory effect of RANKL on proliferation- and apoptosis-related molecules is dependent on IL-8. FCM analysis of Ki-67, Bcl-2, Fas and FasL expression in (A and C) HeLa and (B and D) SiHa cells, which were treated as described in Fig 5. The data are represented as the mean \pm SEM. ${ }^{*} \mathrm{P}<0.05$, ${ }^{* *} \mathrm{P}<0.01$ and ${ }^{* * * *} \mathrm{P}<0.0001$ (one-way ANOVA).

Following treatment with rhIL-8 plus $\alpha$-RANKL, the proliferation and apoptosis capacities in the HeLa and SiHa cells were similar to the group treated with rhIL-8 alone, suggesting that treatment with rhIL-8 reversed the inhibitory effect on 


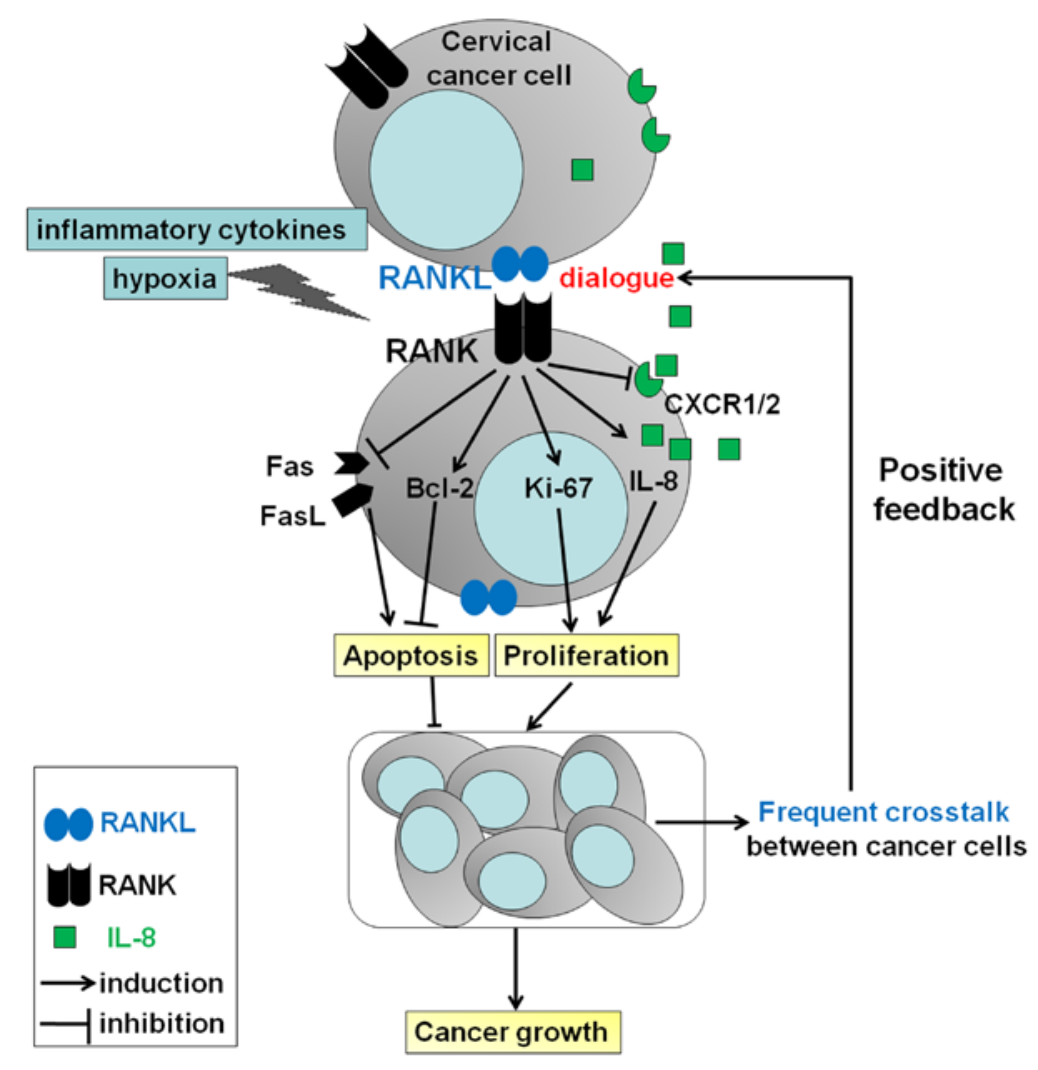

Figure 8. The role of RANKL/RANK interaction in the progression of cervical cancer. A high level of mRANKL and RANK possibly induced by inflammatory cytokines and or hypoxia, results in increased levels of Ki-67 and Bcl-2, and decreased levels of Fas and FasL, that further stimulates the growth of cervical cancer cells and accelerates the development of cervical cancer by strengthening the dialogue between cervical cancer cells and the regulation of IL- 8 secretion. In addition, RANKL represses this effect by downregulating the expression of IL-8 receptors CXCR1 and CXCR2. Accompanied by rapid growth of cervical cancer, the dialogue mediated by mRANKL/RANK becomes more frequent between tumor cells, and the degree of hypoxia is further increased. Hypoxia may amplify the stimulatory effect of RANKL and IL-8 on the growth of cervical cancer cells. These integral effects stimulate the development of cervical cancer.

cell proliferation and the stimulatory effect on cell apoptosis induced by $\alpha$-RANKL (Fig. 6A-D).

We next found that rhIL-8 increased Ki-67 and Bcl-2 expression, and decreased Fas and FasL expression in the HeLa and SiHa cells $(\mathrm{P}<0.05$ or $\mathrm{P}<0.01)$ (Fig. 7A-D). Similarly, it also abrogated the regulatory effect on the levels of these molecules mediated by $\alpha$-RANKL (Fig. 7A-D). Therefore, these findings provide evidence that RANKL may stimulate cervical cancer cell growth by IL-8 production.

\section{Discussion}

Numerous studies have estimated that the RANKL/RANK system mediates important osteoclast-dependent pathological processes in metastatic disease to bone (22). Our previous study also showed that RANKL was involved in the regulation of biological behaviors of decidual stromal cells (23). In the present study, IHC analysis showed that cervical cancer cells had high levels of RANKL and RANK compared to paracancerous cells.

Various factors have been described including hormones and cytokines, such as progesterone, parathyroid hormonerelated protein (PTHrP), vitamin D3, prostaglandin E2 (PGE2), IL-1 $\beta$, IL-6 and TNF $\alpha$ that affect the expression of RANKL and RANK (9). Inflammation is an essential element in tumorigenesis. Abundant evidence supports the preposition that various types of cancers are triggered by infection and chronic inflammatory disease $(24,25)$. In this process, interleukins play a role in cervical carcinogenesis as autocrine and/or paracrine stimuli, such as IL-1 $\beta$, IL- 6 and TNF- $\alpha$ (26). Hypoxia is a common feature in the solid tumor microenvironment, and is caused by the tumor outgrowing the existing vasculature. Moreover, hypoxia upregulates RANK and RANKL expression and increases RANKL-induced cell migration via the PI3K/AKT-hypoxia inducible factor- $1 \alpha$ (HIF-1 $\alpha$ ) pathway (27). Therefore, these inflammatory factors and local hypoxia may contribute to a high level of RANKL/ RANK in cervical cancer cells, and this concept needs further research.

Subsequently, we observed the role of the RANKL/RANK system in the regulation of the biological behaviors of cervical cancer cells, and found that blocking RANKL/RANK interaction by $\alpha$-RANKL or rhOPG could significantly decrease the proliferation and promote the apoptosis of HeLa and SiHa cells. Yet, treatment with rhRANKL showed no obvious regulatory effect. This difference suggests that the stimulatory effect of RANKL on the growth of cervical cancer cells may mainly be dependent on mRANKL/RANK interaction between cervical cancer cells. Further analysis showed that both $\alpha$-RANKL and rhOPG markedly downregulated Ki-67 and $\mathrm{Bcl}-2$ expression and upregulated Fas and FasL expression in the HeLa and $\mathrm{SiHa}$ cells, suggesting that the regulation of 
these proliferation- and apoptosis-related molecules may be involved in the regulatory process of the RANKL/RANKL axis in cervical cancer cell growth.

RANKL binds and activates the receptor RANK, and then induces the NF- $\mathrm{B}, \mathrm{MAPK}$ and PI3K/AKT pathways to control several physiological and pathological processes (28). These signaling pathways (for example, MAPK/ERK1/2, p38, $\mathrm{JNK}, \mathrm{AKT}$ and NF- $\mathrm{NB}$ ) were also proven to be involved in the regulation of cervical cancer cell proliferation and apoptosis (29-31). Therefore, the influence of RANKL on cervical cancer cells may also be achieved by activation of these signaling pathways.

Secchiero et al reported that the RANKL/RANK system may contribute to B-CLL pathogenesis by upregulating IL-8 (20). However, tumor-derived interleukin-8 stimulates osteolysis independent of RANKL (32). These studies suggest that RANKL may be an upstream molecule of IL-8. In the present study, we found that RANKL stimulated IL- 8 secretion from the HeLa and SiHa cells. Owing to the important role of IL-8 in cervical cancer cells (19), we next found that rhIL-8 upregulated Ki-67 and Bcl-2 expression, downregulated Fas and FasL expression, enhanced the proliferation and repressed the apoptosis in HeLa and SiHa cells. In addition, rhIL- 8 reversed the effect of $\alpha$-RANKL on proliferation- and apoptosis-related molecules, proliferation and apoptosis. These data indicate that the RANKL/RANK system promotes cervical cancer cell growth by IL-8. Taking into account the effect of hypoxia on IL- 8 and our current findings, it can be concluded that hypoxia may upregulate RANKL/RANK expression and further stimulate IL-8 secretion consequently promoting cervical cancer cell growth.

FCM analysis showed that RANKL decreased CXCR1 and CXCR2 expression in the HeLa and SiHa cells. These results suggest that RANKL, on the one hand, stimulates IL-8 production and promotes cervical cancer cell growth, yet, on the other hand, forms a negative feedback to control this effect through downregulation of IL- 8 receptors. The possible mechanism should be further studied.

Based on our results and previous studies, as shown in Fig. 8, it can be concluded that a high level of mRANKL/RANK possibly induced by inflammatory cytokines and or hypoxia, results in an increase in $\mathrm{Ki}-67$ and $\mathrm{Bcl}-2$, and a decrease in apoptosis-related molecules Fas and FasL, further promoting the growth of cervical cancer cells and accelerating the development of cervical cancer by strengthening the dialogue between cervical cancer cells and the stimulation of IL-8 secretion. At the same time, RANKL restricts this effect by downregulating IL-8 receptor expression. Accompanied by the rapid growth of cervical cancer, the dialogue mediated by mRANKL/RANK will be promoted between tumor cells, and the degree of hypoxia will further increase. Hypoxia may amplify the stimulatory effect of RANKL and IL- 8 on the growth of cervical cancer cells. These integral effects stimulate the development of cervical cancer. Our data provide new insight into the mechanisms of the RANKL/RANK axis in the pathogenesis of cervical cancer. Related research has shown that administration of the RANKL inhibitor, denosumab (33) and antagonist, RANK-Fc (34) decreases bone metastases and delays tumor progression. These findings have implications for future therapeutic strategies targeting RANKL in cervical cancer, particularly for patients with high expression of RANKL.

\section{Acknowledgements}

The present study was supported by the National Natural Science Foundation of China (NSFC) (81471513), the Training Program for Young Talents of Shanghai Health System (XYQ2013104) and the Program for Zhuoxue of Fudan University (all to M.-Q. Li), the NSFC 81302260 (to F. Xie), and the Research Program for Maternal and Child of Jiangsu Province (F201429) (to J.-J. Yu).

\section{References}

1. Stewart BW and Wild CP (eds): World Cancer Report 2014 World Health Organization. Chapter 5.12. IARC Nonserial Publication, 2014.

2. Fu Z, Chen D, Cheng H and Wang F: Hypoxia-inducible factor-1 $\alpha$ protects cervical carcinoma cells from apoptosis induced by radiation via modulation of vascular endothelial growth factor and p53 under hypoxia. Med Sci Monit 21: 318-325, 2015.

3. Lacey DL, Timms E, Tan HL, Kelley MJ, Dunstan CR, Burgess T, Elliott R, Colombero A, Elliott G, Scully S, et al: Osteoprotegerin ligand is a cytokine that regulates osteoclast differentiation and activation. Cell 93: 165-176, 1998.

4. Anderson DM, Maraskovsky E, Billingsley WL, Dougall WC Tometsko ME, Roux ER, Teepe MC, DuBose RF, Cosman D and Galibert L: A homologue of the TNF receptor and its ligand enhance T-cell growth and dendritic-cell function. Nature 390: 175-179, 1997.

5. Fata JE, Kong YY, Li J, Sasaki T, Irie-Sasaki J, Moorehead RA, Elliott R, Scully S, Voura EB, Lacey DL, et al: The osteoclast differentiation factor osteoprotegerin-ligand is essential for mammary gland development. Cell 103: 41-50, 2000.

6. Schramek D, Leibbrandt A, Sigl V, Kenner L, Pospisilik JA, Lee HJ, Hanada R, Joshi PA, Aliprantis A, Glimcher L, et al: Osteoclast differentiation factor RANKL controls development of progestin-driven mammary cancer. Nature 468: 98-102, 2010.

7. Rossi SW, Kim MY, Leibbrandt A, Parnell SM, Jenkinson WE, Glanville SH, McConnell FM, Scott HS, Penninger JM, Jenkinson EJ, et al: RANK signals from $\mathrm{CD}^{+} 3^{-}$inducer cells regulate development of Aire-expressing epithelial cells in the thymic medulla. J Exp Med 204: 1267-1272, 2007.

8. Jones DH, Nakashima T, Sanchez OH, Kozieradzki I, Komarova SV, Sarosi I, Morony S, Rubin E, Sarao R, Hojilla CV, et al: Regulation of cancer cell migration and bone metastasis by RANKL. Nature 440: 692-696, 2006.

9. Hanada R, Hanada T, Sigl V, Schramek D and Penninger JM: RANKL/RANK-beyond bones. J Mol Med (Berl) 89: 647-656, 2011.

10. Cheng ML and Fong L: Effects of RANKL-targeted therapy in immunity and cancer. Front Oncol 3: 329, 2014.

11. Palafox M, Ferrer I, Pellegrini P, Vila S, Hernandez-Ortega S, Urruticoechea A, Climent F, Soler MT, Muñoz P, Viñals F, et al: RANK induces epithelial-mesenchymal transition and stemness in human mammary epithelial cells and promotes tumorigenesis and metastasis. Cancer Res 72: 2879-2888, 2012.

12. Hsu CJ, Lin TY, Kuo CC, Tsai CH, Lin MZ, Hsu HC, Fong YC and Tang $\mathrm{CH}$ : Involvement of integrin up-regulation in RANKL/RANK pathway of chondrosarcomas migration. J Cell Biochem 111: 138-147, 2010.

13. Armstrong AP, Miller RE, Jones JC, Zhang J, Keller ET and Dougall WC: RANKL acts directly on RANK-expressing prostate tumor cells and mediates migration and expression of tumor metastasis genes. Prostate 68: 92-104, 2008.

14. Chen LM, Kuo CH, Lai TY, Lin YM, Su CC, Hsu HH, Tsai FJ, Tsai $\mathrm{CH}$, Huang CY and Tang $\mathrm{CH}$ : RANKL increases migration of human lung cancer cells through intercellular adhesion molecule-1 up-regulation. J Cell Biochem 112: 933-941, 2011.

15. Murdoch $\mathrm{C}$ and Finn A: Chemokine receptors and their role in inflammation and infectious diseases. Blood 95: 3032-3043, 2000 . 
16. Mantovani A, Savino B, Locati M, Zammataro L, Allavena P and Bonecchi R: The chemokine system in cancer biology and therapy. Cytokine Growth Factor Rev 21: 27-39, 2010.

17. Vicari AP and Caux C: Chemokines in cancer. Cytokine Growth Factor Rev 13: 143-154, 2002.

18. Nickel R, Beck LA, Stellato C and Schleimer RP: Chemokines and allergic disease. J Allergy Clin Immunol 104: 723-742, 1999.

19. Liu LB, Xie F, Chang KK, Li MQ, Meng YH, Wang XH, Li H Li DJ and Yu JJ: Hypoxia promotes the proliferation of cervical carcinoma cells through stimulating the secretion of IL-8. Int J Clin Exp Pathol 7: 575-583, 2014.

20. Secchiero P, Corallini F, Barbarotto E, Melloni E, di Iasio MG, Tiribelli $\mathrm{M}$ and Zauli G: Role of the RANKL/RANK system in the induction of interleukin-8 (IL-8) in B chronic lymphocytic leukemia (B-CLL) cells. J Cell Physiol 207: 158-164, 2006.

21. Xie F, Meng YH, Liu LB, Chang KK, Li H, Li MQ and Li DJ: Cervical carcinoma cells stimulate the angiogenesis through TSLP promoting growth and activation of vascular endothelial cells. Am J Reprod Immunol 70: 69-79, 2013.

22. Chu GC and Chung LW: RANK-mediated signaling network and cancer metastasis. Cancer Metastasis Rev 33: 497-509, 2014.

23. Meng YH, Li H, Chen X, Liu LB, Shao J, Chang KK, Du MR, Jin LP, Li MQ and Li DJ: RANKL promotes the growth of decidual stromal cells in an autocrine manner via CCL2/CCR2 interaction in human early pregnancy. Placenta 34: 663-671, 2013.

24. Deivendran S, Marzook KH and Radhakrishna Pillai M: The role of inflammation in cervical cancer. Adv Exp Med Biol 816: 377-399, 2014

25. Husseinzadeh $\mathrm{N}$ and Davenport SM: Role of toll-like receptors in cervical, endometrial and ovarian cancers: A review. Gynecol Oncol 135: 359-363, 2014.
26. Castrilli G, Tatone D, Diodoro MG, Rosini S, Piantelli M and Musiani P: Interleukin 1alpha and interleukin 6 promote the in vitro growth of both normal and neoplastic human cervical epithelial cells. Br J Cancer 75: 855-859, 1997.

27. Tang ZN, Zhang F, Tang P, Qi XW and Jiang J: Hypoxia induces RANK and RANKL expression by activating HIF-1 $\alpha$ in breast cancer cells. Biochem Biophys Res Commun 408: 411-416, 2011.

28. Wada T, Nakashima T, Hiroshi N and Penninger JM: RANKLRANK signaling in osteoclastogenesis and bone disease. Trends Mol Med 12: 17-25, 2006.

29. Wang L, Guo H, Yang L, Dong L, Lin C, Zhang J, Lin P and Wang X: Morusin inhibits human cervical cancer stem cell growth and migration through attenuation of NF- $\mathrm{BB}$ activity and apoptosis induction. Mol Cell Biochem 379: 7-18, 2013.

30. Kim SH, Kim SH, Kim YB, Jeon YT, Lee SC and Song YS: Genistein inhibits cell growth by modulating various mitogenactivated protein kinases and AKT in cervical cancer cells. Ann NY Acad Sci 1171: 495-500, 2009.

31. Rashmi R, DeSelm C, Helms C, Bowcock A, Rogers BE, Rader JL, Grigsby PW and Schwarz JK: AKT inhibitors promote cell death in cervical cancer through disruption of mTOR signaling and glucose uptake. PLoS One 9: e92948, 2014.

32. Bendre MS, Margulies AG, Walser B, Akel NS, Bhattacharrya S, Skinner RA, Swain F, Ramani V, Mohammad KS, Wessner LL, et al: Tumor-derived interleukin-8 stimulates osteolysis independent of the receptor activator of nuclear factor-kappaB ligand pathway. Cancer Res 65: 11001-11009, 2005.

33. Bouganim $\mathrm{N}$ and Clemons MJ: Bone-targeted agents in the treatment of bone metastases: RANK outsider or new kid on the block? Future Oncol 7: 381-383, 2011.

34. Sordillo EM and Pearse RN: RANK-Fc: A therapeutic antagonist for RANK-L in myeloma. Cancer 97 (Suppl): S802-S812, 2003. 